BANGLADESH J CHILD HEALTH 2010; VOL 34 (2): 70-72

\title{
A Neonate with Non-immune Hydrops Foetalis in Rh Non-immunized Mother
}

\author{
NURJAHAN BEGUM ${ }^{1}$, REZAUL KARIM KAZAL ${ }^{2}$, SHAHEEN ARAANWARY $^{3}$, KHADIZANURUN NAHAR $^{4}$, \\ PARVEEN AKHTER SHAMSUNNAHAR ${ }^{5}$, NARGIS AKHTER ${ }^{6}$
}

\section{Introduction}

Hydrops foetalis is a serious foetal condition defined as the presence of excess fluid in more than one body compartment. The fluid should be present in any of the following two cavities to be diagnosed as hydrops foetalis e.g., subcutaneous tissue, lung, abdominal cavity and pericardial cavity ${ }^{1}$. The incidence of hydrops is difficult to ascertain as most of foetuses die early in pregnancy. However, in USA its incidence is approximately one in 600 to one in $4000^{1}$. In Southeast Asia it is more common and its incidence varies from one in 500 to one in $1500^{2}$. There are two types of hydrops foetalis: 1. Immune hydrops foetalis (IHF) 2. Non-immune hydrops foetalis (NIHF)

With the use of anti $D$ prophylaxis immunological causes account for less than $20 \%$ cases $^{1}$. More common are non-immune causes of hydrops foetalis ${ }^{3}$. The cause of non-immune hydrops foetalis is often idiopathic ${ }^{4}$. The common cause of non-immune hydrops foetalis in order of decreasing frequency are vascular (20\%), chromosomal (16\%), placental (8\%), haematological (10\%) and a miscellaneous group ${ }^{5,6}$. Hydrops foetalis due to maternal cause is rare and is usually due to infection or diabetes mellitus in the mother ${ }^{6}$. Intrauterine infection accounts only $8 \%$ of non-immune hydrops foetalis. Non-immune hydrops foetalis is mainly due to foetal causes ${ }^{7}$.

\section{Case Report}

Thirty two years old woman, third gravida, mother of two children, presented at forty weeks of pregnancy with labour pain for fourteen hours. The mother had no antenatal care (ANC) and suffered from respiratory distress at later months of present pregnancy. Her previous two pregnancies were naturally terminated at home by spontaneous vaginal delivery. According to mother's statement her first baby was hydrops, alive for about 2 minutes and second baby was apparently healthy and still alive. Blood group of father,

1. Senior Consultant, Department of Obstetrics and Gynaecology, BSMMU, Dhaka

2. Assistant Professor, Department of Obstetrics and Gynaecology, BSMMU, Dhaka

Correspondence: Dr. Nurjahan Begum and elder alive child were A positive, and $A B$ positive. Study on peripheral blood and level of haemoglobin of both parents and elder sister did not show any features of anaemia or red cell abnormality. Mother's blood group was B negative and preoperative Rh antibody was undetectable in mother's blood. Mother's blood sugar was $7 \mathrm{mmol} / \mathrm{l}$. VDRL of both parents are nonreactive. There was no relevant history of maternal infection in any pregnancy and no history of abortion. Mother took no antenatal care (ANC), no Rh anti D prophylaxis and no Rh positive blood transfusion in the three pregnancies. Ultrasonogram of present pregnancy revealed single foetus, longitudinal lie of foetus, breech presentation, scalp and subcutaneous tissue oedema, hydrothorax, massive ascites and polyhydramnios but no gross congenital anomaly was detected.

On general examination, the mother was moderately anaemic, normotensive, oedema, Jaundice and cyanosis were absent. Systemic examination revealed no abnormality. Per abdominal examination of the mother prior to delivery showed abdomen was hugely enlarged and presentation and lie of the foetus could not be delineated. Foetal heart sound was not audible by ordinary stethoscope but mother perceived foetal movements, ultrasonogram showed both foetal and cardiac movement.

Emergency caesarean section was done for prolonged labour. At birth the neonate was grossly oedematous, drowsy, pale and severely asphyxiated with gasping respiration but had no body or limb movement (Fig.1). On detailed physical examination of the baby, growth parameter showed an abnormally enlarged thorax and abdomen but no associated congenital malformations. The neonate had generalized and vulval oedema. Her colour was pale, heart rate was 130 / minute and respiratory rate was 20 /minute, irregular and gasping. Immediate after birth the neonate was actively resuscitated with bag and mask ventilation. During resuscitation, she tried for cry several times but failed and expired at about six minutes of life. Cord blood was submitted for blood group, Rh typing and direct Coombs' test. Cord blood haemoglobin was 


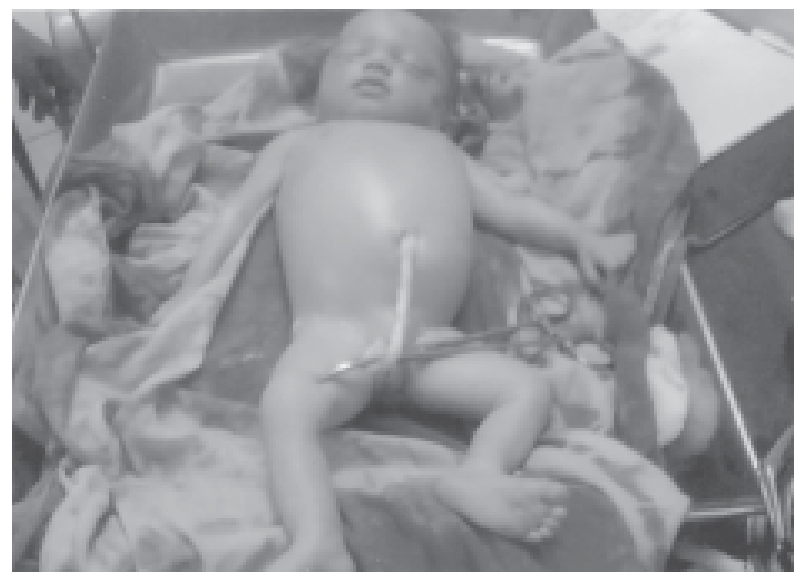

Fig.-1 : Neonate after birth

$5 \mathrm{gm} / \mathrm{dl}$, blood group was AB positive but unfortunately direct Coombs' test was not done. Features detected by preoperative ultrasound scan, post delivery physical findings and on investigation very low cord blood haemoglobin suggested that the neonate was hydrops. Since history and investigations did not illustrate the immune cause of hydrops foetalis, the pathogenesis of hydrops foetalis in this neonate was most probably of the non-immune type and may be idiopathic. So, it is hard for this mother for adequate/ optimum management and prevention of hydrops fetalis in subsequent pregnancies.

\section{Discussion}

The relative incidence of hydrops foetalis has changed dramatically in the past 20 years due to prevention of immune related hydrops fetalis secondary to Rhesus isoimmunization by $R$ h anti $D$ prophylaxis ${ }^{7}$. So, the incidence of NIHF is more than hydrops foetalis ${ }^{8}$. The maternal risk factors for the development of non immune hydrops foetalis include polyhydramnias (50\%), hypertension, similar illness in previous pregnancy, ethnic background particularly for alpha thalassaemia, placentomegaly, chronic maternal illness like anaemia, glucose-6 phosphate deficiency, diabetes mellitus, infections and drug ingestion ${ }^{9}$. The plausible explanation of the pathogenesis of NIHF due to maternal infection is severe hepatitis leading to hypoalbuminaemia and portal hypertension. Besides, the bone marrow may be suppressed resulting in anaemia and congestive cardiac failure ${ }^{9}$. Antenatal ultrasound scan permits the detection, monitoring and often helps to determine the cause of hydrops foetalis ${ }^{9}$. Non-imrnune hydrops can occur at any time during pregnancy ${ }^{3}$. In general NIHF is regarded to have poor prognosis and usually termination of pregnancy is advisable ${ }^{10}$. The prognosis is even poorer if hydrops is diagnosed in the first half of pregnancy ${ }^{11}$. There is no standard and effective treatment for NIHF still now ${ }^{3}$. Neonatologists are trying best for treating non-immune hydrops fetalis during intrauterine period and immediately after birth. Intrauterine therapy includes appropriate removal of amniotic fluid, management of cardiac arrhythmias, early referral to level III neonatal center, fetal thoracocentesis and / or peritoneocentesis (for the growth of the lung) ${ }^{12}$.

The management at birth includes aggressive resuscitation, appropriate fluid therapy, diuresis, dialysis, treatment of cardiac failure, partial or total exchange transfusion if PCV is less than $25 \%{ }^{4}$ and treatment of underlying cause ${ }^{9}$. The outcome is favourable in conditions like cardiac arrhythmias, frequent blood transfusion to the mother and twin to twin transfusions. However, in other conditions, like congenital infection, chromosomal aberrations and metabolic disorders despite early detection and aggressive management, the prognosis is poor ${ }^{6,9}$. The mortality rate of NIHF varies from 50 to $95 \%$ and the prognosis depends on the aetiology of the condition ${ }^{7}$. Very few cases of complete resolution of HF of unknown aetiology are described in some literatures; Henrich ${ }^{1}$ described complete resolution of severe non-immune hydrops fetalis in second trimester. Swin et al ${ }^{13}$ described survival of two cases of hydrops of idiopathic etiology.

In this case, etiology may be due to chromosomal aberrations or heart disease. In such type of cases we should counsel the couple that HF could not be preventable and hydrops baby usually can not continue life except some correctable conditions e.g., congenital heart disease and some cases of diaphragmatic hernia as management aids and skill are not optimum in our country.

\section{Conclusion}

In presence of immune factors (Rh Negative mother and Rh Positive father) NIHF is a very rare condition and due to its rarity / scarcity much information is not available. Though rare, obstetricians should keep in mind that $\mathrm{Rh}$ non-immunized mother without consanguineous marriage may give birth of a NIHF and should be diagnosed early during ANC and consider 
termination of pregnancy in non-correctable conditions of NIHF. Obstetrician also could make all reasonable efforts to find out the clue of etiologic agent and dealt accordingly.

\section{References}

1. Henrich W, Heeger J, Schmider A, Dudenhausen JW. Complete Spontaneous resolution of severe non-immunological hydrops fetalis with unknown etiology in the second trimester - A case report. J Perinat Med 2002; 30: 522-27.

2. Hamdan AH. Hydrops fetalis, eMedicine 22, 2006.

3. Ali HS. Spontaneous resolution of Non-immune Hydrops fetalis. Pak J Med Sci 2008; 24: 62123.

4. NRC Roberton. Hydrops fetalis. In: A manual of neonatal intensive care. $2^{\text {nd }}$ ed. London: English language Book Society/Edward Armold, 1988.

5. Harahan D, Murphy JF, O'Brien N, Gorman W, Kelehan P, Cullinane C, et al. Clinico-pathological findings in non-immune hydrops fetalis. Ir Med J 1991; 84: 62-63.

6. Poeschmann RP, Verheijen $\mathrm{RH}$, Van Dongen PW. Differential diagnosis and causes of nonimmunological hydrops fetalis: a review. Obstet Gynaecol Surv 1991; 46: 223-31.
7. Ram SP, Ariffin WA, Kassim Z. Case report - a neonate with non-immune hydrops fetalis. Singapore Med J 1993; 34: 459-61.

8. DC Wilson, HL Halliday, G McClure, MMcC Reid. The Changing pattern of fetal Hydrops. Ulster Med J 1990; 59: 119-21.

9. McGillivray BC, Hall JG . Non-immune hydrops fetalis. Pediatr Rev 1987; 9: 197-202.

10. Rodis JF, Quinn DL, Gary GW Jr, Anderson LJ, Rosengren S, Cartter ML, et al. Management and outcomes of pregnancies complicated by human B-19 parvovirus infection: A prospective study. Am J Obstet Gynecol 1990; 163: 116871.

11. Ericgauniause IJ. Outcome of NIHF diagnosed during the first half of pregnancy. Obstet Gynae 1997; 90: 321-25.

12. Shimokawa $\mathrm{H}$, Hara $\mathrm{K}$, Maeda $\mathrm{H}$, Miyamoto $\mathrm{S}$, Koyanagi T, Nakano H. Intrauterine treatment of idiopathic hydrops fetalis. J Perinat Med 1988; 16: 133-38.

13. Swain S, Cameron AD, McNay MB, Howatson AG. Prenatal diagnosis and management of nonimmunological hydrops fetalis. Aust NZJ Obstet Gynaecol 1999; 39: 285-90. 